\title{
Relationships between dimensions of disability experienced by adults living with HIV: A structural equation model analysis
}

Kelly K. O’Brien, Aileen M. Davis, Sandra Gardner, Ahmed M. Bayoumi, Sergio Rueda, Trevor A. Hart, Curtis Cooper, Patricia Solomon, Sean B. Rourke, Steven Hanna, and the OHTN Cohort Study Team

Version Post-Print/Accepted Manuscript

Citation O'Brien KK, Davis AM, Gardner S, Bayoumi AM, Rueda S, Hart T, (published version) Cooper C, Solomon P, Rourke S, Hanna S, and the OHTN Cohort Study Team. Relationships between dimensions of disability experienced by adults living with HIV: A structural equation model analysis. AIDS and Behavior. 2014 18:357-367. DOI: 10.1007/s10461012-0363-2

Publisher's Statement The final publication is available at Springer via http://dx.doi.org/10.1007/s10461-012-0363-2 


\title{
Relationships between dimensions of disability experienced by adults living with HIV: A structural equation model analysis
}

Kelly K. O’Brien; Aileen M. Davis; Sandra Gardner; Ahmed M. Bayoumi; Sergio Rueda; Trevor A. Hart; Curtis Cooper; Patricia Solomon; Sean B. Rourke; Steven Hanna; and the OHTN Cohort Study Team*

\section{Kelly K. O'Brien}

Department of Physical Therapy, University of Toronto, Toronto, Ontario, Canada

School of Rehabilitation Science, McMaster University, Hamilton, Ontario, Canada

\author{
Aileen M. Davis \\ University Health Network, Toronto Western Research Institute, Toronto, Ontario, Canada \\ Institute of Health Policy, Management and Evaluation, University of Toronto, Toronto, Ontario, \\ Canada
}

\section{Sandra Gardner}

The Ontario HIV Treatment Network, Toronto, Ontario, Canada

\section{Ahmed M. Bayoumi}

Centre for Research on Inner City Health, Keenan Research Centre of the Li Ka Shing Knowledge Institute, St. Michael’s Hospital, Toronto, Ontario, Canada

Institute of Health Policy, Management and Evaluation, University of Toronto, Toronto, Ontario, Canada

Department of Medicine, University of Toronto, Toronto, Ontario, Canada

\section{Sergio Rueda}

The Ontario HIV Treatment Network, Toronto, Ontario, Canada 
Trevor A. Hart

Ryerson University, Department of Psychology, Toronto, Ontario, Canada

Dalla Lana School of Public Health, University of Toronto, Toronto, Ontario, Canada

\section{Curtis Cooper}

University of Ottawa, Division of Infectious Diseases, The Ottawa Hospital

Ottawa, Ontario, Canada

\section{Patricia Solomon}

School of Rehabilitation Science, McMaster University, Hamilton, Ontario, Canada

\section{Sean B. Rourke}

The Ontario HIV Treatment Network, Toronto, Ontario, Canada

Centre for Research on Inner City Health, Keenan Research Centre of the Li Ka Shing

Knowledge Institute, St. Michael's Hospital, Toronto, Ontario, Canada

Department of Psychiatry, University of Toronto, Toronto, Ontario, Canada

\section{Steven Hanna}

Department of Clinical Epidemiology and Biostatistics, McMaster University, Hamilton, Ontario, Canada

Running Head: Relationships between Dimensions of Disability among Adults Living with HIV

\section{Author Designated to Review Proofs}

Kelly O’Brien

Department of Physical Therapy, University of Toronto 
500 University Avenue, Room 160

Toronto, Ontario, Canada M5G 1V7

Phone: 416-978-0565;

Fax: 416-946-8562;

Email: kelly.obrien@utoronto.ca

\section{ACKNOWLEGEMENTS}

This work was supported by the Canadian Institutes of Health Research (CIHR) and McMaster University DeGroote Postdoctoral Fellowship. Kelly O’Brien was supported by a Fellowship from the CIHR, HIV/AIDS Research Initiative. Trevor Hart is supported by an OHTN Career

Scientist Award. We thank Carolina BarnettTapia for translating the abstract into Spanish.

*The OHTN Cohort Study Team consists of Dr. Sean B. Rourke (Principal Investigator, University of Toronto and OHTN), Dr. Ann Burchell (Co-Principal Investigator, OHTN), Dr. Sandra Gardner (OHTN), Dr. Sergio Rueda (OHTN), Dr. Ahmed Bayoumi, St. Michael's Hospital; Dr. Jeffrey Cohen, Windsor Regional Hospital; Dr. Curtis Cooper, Ottawa General Hospital; Dr. Don Kilby, University of Ottawa Health Services; Dr. Mona Loutfy and Dr. Fred Crouzat, Maple Leaf Medical Clinic; Dr. Anita Rachlis and Dr. Nicole Mittmann, Sunnybrook Health Sciences Centre; Dr. Janet Raboud and Dr. Irving Salit, Toronto General Hospital; Dr. Edward Ralph, St. Joseph's Health Care; Dr. Roger Sandre, Sudbury Regional Hospital; Dr. Marek Smieja, Hamilton Health Sciences, McMaster University Medical Centre; and Dr. Wendy Wobeser, Hotel Dieu Hospital.

We gratefully acknowledge all of the people living with HIV who volunteered to participate in the OHTN Cohort Study and the work and support of the past and present members of the OCS Governance Committee: Dr. Evan Collins, Dr. Greg Robinson, Shari Margolese, Patrick Cupido, 
Tony Di Pede, Rick Kennedy, Michael J. Hamilton, Ken King, Brian Finch, Lori Stoltz, Dr. Ahmed Bayoumi, Dr. Clemon George, Dr. Curtis Cooper, Dr. Troy Grennan, Adrian Betts, Tracey Conway, and Colleen Price. We thank all the interviewers, data collectors, research associates and coordinators, nurses and physicians who provide support for data collection and extraction. The authors wish to thank the OHTN staff and their teams for data management and IT support (Mark Fisher, Director, IT), and OCS project coordination (Samantha Robinson, Project Coordinator). The OHTN Cohort Study is supported by the Ontario Ministry of Health and Long-Term Care. The opinions, results and conclusions are those of the authors and no endorsement by the Ontario HIV Treatment Network is intended or should be inferred. 


\title{
Relationships between dimensions of disability experienced by adults living with HIV: A structural equation model analysis
}

\begin{abstract}
As individuals age with HIV it is increasingly important to consider the health-related consequences of HIV and multiple morbidities, known as disability. We assessed relationships between four dimensions of disability among adults living with HIV. We conducted a structural equation modeling analysis using data from 913 participants in the Ontario HIV Treatment Network Cohort Study to determine relationships between four latent variables of disability in the Episodic Disability Framework: physical symptoms and impairments, mental health symptoms and impairments, difficulties with day-to-day activities, and challenges to social inclusion. Results indicated that physical symptoms and impairments, mental health symptoms and impairments and difficulties with day-to-day activities directly or indirectly predicted challenges to social inclusion for adults living with HIV. Challenges to social inclusion were directly predicted by mental health symptoms and indirectly by physical health symptoms via (mediated by) having difficulties carrying out day-to-day activities and mental health symptoms and impairments. These findings provide a basis for conceptualizing disability experienced by people living with HIV.
\end{abstract}

Key Words - HIV/AIDS; disability; structural equation modeling 


\title{
Relaciones entre dimensiones de discapacidad experimentadas por adultos viviendo con VIH: Un análisis de Ecuaciones Estructurales
}

\author{
RESUMEN \\ Cuando los individuos con VIH envejecen, se hace cada vez más importante considerar las \\ consecuencias del VIH en la salud y sus múltiples comorbilidades, conocidas como \\ discapacidad. Evaluamos las relaciones entre cuatro dimensiones de discapacidad entre adultos \\ viviendo con VIH. Realizamos un análisis de ecuaciones estructurales usando los datos de 913 \\ participantes en el Estudio de Cohorte de la Red de Tratamiento de VIH de Ontario, para \\ determinar las relaciones entre cuatro variables latentes de discapacidad en el Marco Episódico \\ de Discapacidad: síntomas físicos y deficiencias, síntomas de salud mental y deficiencias, \\ dificultades con actividades del día a día, y desafíos a la inclusión social de adultos viviendo con \\ VIH, indirectamente predichos. Los desafíos a la inclusión social fueron predichos directamente \\ por síntomas de salud mental e indirectamente por síntomas de salud física vía (mediado por) \\ tener dificultades llevando a cabo actividades del día a día y síntomas y deficiencias de salud \\ mental. Estos hallazgos proveen una base para conceptualizar la discapacidad experimentada por \\ las personas viviendo con VIH.
}




\section{INTRODUCTION}

As more individuals live longer and age with HIV, they may be living with health challenges associated with HIV and potential adverse effects of treatments. The premature onset of cardiovascular disease, diabetes [1], bone and joint disorders [2, 3], neurocognitive disorders [4] and non-AIDS-defining cancers [5], add further complexity to the health challenges experienced by adults with HIV. Hence, it is increasingly important for clinicians to consider the healthrelated consequences of HIV [6-8] and multiple morbidities $[9,10]$, such as fatigue, weakness, pain, and changes in body composition to difficulties participating in society, such as employment [11-13]. These health-related challenges may be collectively termed disability [14].

The Episodic Disability Framework is a conceptual framework developed from the perspective of adults living with HIV to describe and understand disability experienced by adults living with HIV [14]. In this Framework, adults living with HIV conceptualized disability as multi-dimensional and episodic in nature characterized by periods of wellness and illness. The Episodic Disability Framework is comprised of three main components. The first component, dimensions of disability, includes a) symptoms and impairments (e.g. physical, mental and emotional health challenges), b) difficulties carrying out day-to-day activities (e.g. difficulties with walking, activities of daily living, carrying out household chores), c) challenges to social inclusion (e.g. challenges fulfilling roles as a parent, difficulties engaging in work and school, and personal relationships), and d) uncertainty about future health (e.g. worrying about the future and the impact of uncertainty on life decisions) that may fluctuate on a daily basis and over the entire course of living with HIV. The second component of the Framework includes extrinsic contextual factors (social support and stigma) and intrinsic contextual factors (living strategies and personal attributes) that may influence dimensions of disability resulting in exacerbations or 
alleviations in disability presence and severity. The third component of the Framework includes triggers or life events that may initiate a major or momentous episode of disability such as receiving a diagnosis, starting or changing antiretroviral medications, experiencing an illness, or suffering a loss of others $[14,15]$. Components of this Framework interact over time resulting in an episodic form of disability. For example, receiving a diagnosis of HIV (trigger) may initiate an episode of disability characterized by physical and mental health symptoms and impairments, difficulties carrying out daily activities and uncertainty about future health (dimensions of disability). This disability may be alleviated by practical or emotional support from friends or family (extrinsic contextual factor), or living strategies, such as adopting positive attitudes and beliefs to help manage living with HIV (intrinsic contextual factor). Alternatively, these challenges may be exacerbated by concurrent health conditions (personal attributes; intrinsic contextual factor) and stigma experienced from employers or family (extrinsic contextual factor). Hence, disability as articulated in the Episodic Disability Framework is a dynamic process that may involve the complex interaction between disability, contextual factors, and triggers over time.

This Framework goes beyond existing frameworks which were developed prior to the advent of combination antiretroviral therapy and were not developed specifically from the perspectives of people living with HIV [16-21]. Furthermore, 'disability' differs from other health-related concepts such as health and quality of life, which are broader in scope and more difficult to ascertain because they consider personal goals, values and expectations [22], whereas disability specifically describes the impact HIV and other concurrent health conditions may have on a person's body, activities and participation in society [23]. Better understanding the disability experience may help to promote timely and appropriate access to interventions and 
services that will help to reduce or prevent disablement and improve the overall health among people living with HIV.

Although this Episodic Disability Framework offers a new way to conceptualize HIVrelated disability, the relationships between the components in this Framework are unknown. However, relationships among other health-related concepts have been explored in the context of HIV infection that may inform hypothesized relationships between components of disability in the Framework $[22,24]$. Previous research assessing a conceptual framework of health-related quality of life with people living with HIV indicated that health concepts span a continuum whereby physiological variables predict symptom status, which in turn predicts functional health status, general health perception and overall quality of life. Further empirical work suggested that symptom status directly predicted general health perception and overall quality of life and that the relationship between symptom status and quality of life was partially mediated by functional health among people with $\operatorname{HIV}[25,26]$.

We used these observed relationships to inform our theory of the relationships between dimensions of disability in the Episodic Disability Framework. However, concepts, such as symptom status and functional health in the quality of life framework, while analogous to symptoms and impairments and difficulties with day-to-day activities in the Episodic Disability Framework, refer to broader concepts and do not consider the distinct relationships between physical and mental health symptoms and their influence on other components of disability. Hence, we assessed the relationships between four dimensions of disability in the Episodic Disability Framework [14]. Findings will provide a foundation for better understanding disability among people living with HIV. 


\section{METHODS}

We used structural equation modeling (SEM) to test relationships between dimensions of disability in the Episodic Disability Framework. Specifically, we conducted an SEM analysis to determine the direction and magnitude of relationships between latent variables of disability using cross-sectional data from the Ontario HIV Treatment Network Cohort Study (OCS) [27]. The OCS is a longitudinal multi-site observational cohort study which collects clinical and sociobehavioral data from HIV-positive adults who are residents of Ontario [27]. Participants complete an interview-administered questionnaire at yearly intervals. We focused our analysis on participants in three sites in Toronto, Ontario who completed a 90 to 120 minute questionnaire comprised of detailed health status instruments and questions related to education, employment status, housing, and income. This study was approved by the OCS Governance Committee and by Research Ethics Boards at McMaster University, and Ryerson University.

\section{Variables}

We used a combination of summary, subscale and item scores from the OCS questionnaire for our model. We used item scores from the HIV Symptom Index, a 20-item questionnaire that describes the presence and burdensome nature of symptoms experienced by adults with HIV [28]. We used seven subscale scores from the SF-36 questionnaire including physical function, role limitation physical, bodily pain, vitality, role limitation emotional, mental health, and social function $[29,30]$. We included item scores from the EQ-5D EuroQoL Questionnaire, a standardized general measure of health related quality of life, comprised of five items (mobility, self-care, usual activities, pain and discomfort, and anxiety and depression) [31]. We used summary scores from the Medical Outcomes Study Cognitive Functioning Scale that measures reasoning and problem solving, memory, attention, and concentration and thinking [32], the 
Center for Epidemiologic Studies for Depression Scale (CES-D), a 20-item instrument that measures depressive symptomatology [33], and the Ongoing Problems Stress Index, a component of the National Population Health Survey Stress Questionnaire [34]. Remaining variables for our model were item scores generated from questions specifically derived for the OCS questionnaire including housing, employment status, education, income, and occupation.

\author{
Analysis \\ Structural equation modeling (SEM) is a statistical technique used to test theoretical models that \\ indicate causal relationships between latent variables (variables that are not directly observed) \\ [35]. SEM analysis has two distinct steps. First, we derived the latent variables from the \\ observed variables in the OCS questionnaire. This step yielded a measurement model. Next, we \\ determined the relationships between the latent variables, which represented the dimensions of \\ disability. This step yielded a structural model. \\ Measurement Model \\ We established a measurement model that included latent variables that represented four \\ dimensions of disability in the Episodic Disability Framework (physical and mental health \\ symptoms and impairments, difficulties with day-to-day activities, and challenges to social \\ inclusion) [36]. We built the model using confirmatory factor analysis with observed measures \\ in the OCS questionnaire and informed by previous literature on quality of life research in HIV, \\ as noted above $[25,26]$. We allocated observed measures to latent variables based on categories \\ that corresponded to each dimension in the Episodic Disability Framework [14, 37]. We further \\ divided symptoms and impairments into physical and mental health symptoms, because, while \\ correlated, these variables differ conceptually [38]. Further details on our development of the \\ measurement model are published elsewhere [36].
}




\section{Structural Model}

Using the latent variables in the measurement model, we established a structural model to assess the direct and indirect (mediating) effects between the dimensions of disability. We hypothesized that there would be both direct and indirect relationships between dimensions of disability in the Episodic Disability Framework (Figure 1). Our hypothesized structural model was based on previously discussed models of symptoms, functional status, and quality of life in the context of HIV [22, 24-26].

We used Mplus version 6.0 statistical software [39] and the weighted least squares method of estimation, which is used with combinations of continuous and categorical variables and non-normally distributed data [40]. Prior to our analysis, we recoded all 'don't know' or 'refused' item responses in the OCS questionnaire to missing values. Where possible, we used subscale or summary scores to simplify the measurement model. We estimated and reported standardized parameter estimates because variables possessed different units of measurement including item, subscale and summary scores that were discrete (categorical) or continuous in nature. Missing data were dealt with using pairwise deletion with the weighted least squares method of estimation [40].

We considered a Root Mean Square Error of Approximation (RMSEA) $<0.05$, Comparative Fit Index $(\mathrm{CFI}) \geq 0.95$, and Tucker Lewis Index (TLI) $\geq 0.95$ to indicate good model fit [41]. We considered the RMSEA as the primary statistic for overall goodness of model fit because it is recommended for confirmatory factor analysis, which is used in structural equation modeling [42]. We reported the chi square statistic $\left(\chi^{2}\right)$ but did not consider it a determinant of model fit given its sensitivity to large sample sizes, which tend to overestimate lack of model fit 
$[35,43]$. For the measurement model, we considered standardized coefficients (factor loadings) $\geq 0.30(\mathrm{p}<0.05)$ as 'representing' a given dimension of disability [43]. For the structural model, we classified standardized path coefficients of $\geq 0.2-0.5$ as a medium (moderate) effect and $>0.5$ a large (strong) effect [35].

\section{Sample Size Estimation}

At least five observations per unknown parameter estimate is required for structural equation modeling [35, 43]. Our primary hypothesized structural model had 93 unknown parameter estimates that included factor loadings and error variances for each of the indicator variables $(\mathrm{n}=83)$, plus latent variable variances $(\mathrm{n}=4)$ and parameter estimates between latent variables $(\mathrm{n}=6)$. Hence we required at least 465 observations for our analysis.

\section{RESULTS}

We analyzed data from 913 adults living with HIV who completed an OCS questionnaire between October 2007 and March 2009 in Toronto, Ontario. Participants were primarily male (83\%) and taking antiretroviral therapy (86\%). The median age was 47 years and the median length of time since diagnosis was 11 years (Table 1).

\section{Measurement model}

Our measurement model that provided the best fit to the data included 43 measured variables in the OCS questionnaire that represented four dimensions of disability (Table 2). Physical symptoms and impairments were represented by 21 variables in the OCS (physical), mental health symptoms and impairments were represented by 10 variables (physical), difficulties with day-to-day activities by 5 variables (day), and challenges to social inclusion by 8 variables (social) (Table 2). The median percent of missing values across all variables was $<2 \%$ (range 0 - 
3.5\%). Correlations coefficients ranged from 0 to 0.74 between contrasting (HIV Symptom Index - Diarrhea and gross personal income) and similar (HIV Symptom Index - Felt Sad and the SF-36 Mental Health Subscale Score) measured variables, respectively. Complete correlation matrices of the measured variables included in the model are available upon request. The RMSEA goodness of fit statistic of 0.048 met our a priori criterion and all OCS variables loaded on at least one dimension of disability (factor loadings $\geq 0.03$ ).

We allowed the SF-36 social function subscale scores to load on both physical symptoms (0.21) and mental health symptoms dimensions (0.61). Although the factor loading on physical symptoms was $<0.30$, we retained this cross loading in the model for two reasons. First, allowing the SF-36 social function summary score to load on both physical and mental health symptoms and impairments improved the model fit by reducing the RMSEA from 0.053 to 0.048. Second, we considered this cross loading to be reasonable because the subscale items included phrasing that referred to how physical and emotional problems interfered with social activities [36].

\section{Structural Equation Model - Relationships between Dimensions of Disability}

Direct Effects: Physical symptoms and impairments were a direct strong predictor of mental health symptoms and impairments (standardized path coefficient: $0.790 ; \mathrm{p}<0.001$ ) and difficulties with day-to-day activities $(0.805 ; \mathrm{p}<0.001)$ (Figure 2$)$. Difficulties with day-to-day activities were a direct moderate predictor of challenges to social inclusion $(0.297 ; \mathrm{p}<0.001)$. Mental health symptoms and impairments were a direct strong predictor of challenges to social inclusion $(0.541 ; \mathrm{p}<0.001)$. The direct relationship between mental health symptoms and challenges to social inclusion is interpreted as, for every one standard deviation increase in mental health symptoms there is a 0.541 standard deviation increase in challenges to social 
inclusion while adjusting for physical health symptoms and impairments and difficulties with day-to-day activities.

Indirect Effects: The effect of physical symptoms and impairments on challenges to social inclusion was mediated by having difficulties with day-to-day activities $(0.239 ; \mathrm{p}<0.001)$ and mental health symptoms and impairments $(0.427 ; \mathrm{p}<0.001)$ (Figure 2$)$. The relationship between mental health symptoms and impairments and difficulties with day-to-day activities was not significant (Figure 2). Almost all (98\%) of the total effect of physical health symptoms and impairments on challenges to social inclusion was mediated through mental health symptoms and impairments. For instance, the total effect of physical symptoms on challenges to social inclusion was the sum of three possible paths, i) the indirect effect of physical to social via mental (0.427), ii) the indirect effect of physical to social via day (0.239) and iii) the direct effect of physical to social $(-0.230)$ which equals 0.436 . Hence the mediated effect between physical health symptoms and impairments to challenges to social inclusion via mental health challenges was $0.427 / 0.436$ (98\% of total effect) (Figure 2).

\section{DISCUSSION}

This is the first study to assess relationships between dimensions of disability in the Episodic Disability Framework for adults living with HIV. Physical symptoms and impairments, mental health symptoms and impairments and difficulties with day-to-day activities directly or indirectly predicted challenges to social inclusion for adults living with HIV. Challenges to social inclusion were directly predicted by mental health symptoms and indirectly by physical health symptoms via (mediated by) having difficulties carrying out day-to-day activities and mental health symptoms and impairments (Figure 2). 
The relationship between physical symptoms and impairments to difficulties with day-today activities was the strongest predictor $(0.805)$ in the model. This result aligns with previous evidence that illustrated direct relationships between physical symptoms such as pain, fever, nausea or loss of appetite and limitations in self-care activities and functional health among adults living with HIV $[26,44,45]$. The mediated relationship between physical symptoms and impairments and challenges to social inclusion through difficulties with day-to-day activities $(0.239)$ is also supported by evidence that demonstrated greater physical symptoms related to greater limitations in social and role functioning for adults living with HIV such as employment, school, recreational activities, and social events $[24,44,46]$. The negative path coefficient from physical symptoms and impairments to challenges to social inclusion in our model $(-0.230$; $\mathrm{p}=0.011$ ) does not suggest that physical symptoms reduce challenges to social inclusion as they are positively correlated in the correlation matrices (available upon request). Rather this finding further highlights the almost full mediation of physical symptoms to challenges to social inclusion via mental health symptoms and impairments.

Our original hypothesized relationship between mental health symptoms and impairments and difficulties with day-to-day activities was not significant in the model (Figure 2). Previous exploration of relationships between components of health-related quality of life with people living with HIV demonstrated strong relationships between symptoms and decreases in physical function or functional health $[22,47-50]$. In these models, symptoms included both physical and mental health challenges, whereas we considered these distinct concepts in our analysis, because while correlated, they differ conceptually [38]. This enabled us to distinguish between the strong direct predictive effect of physical symptoms (0.805), and no effect of mental health symptoms, on difficulties carrying out day-to-day activities. 
The relationship between physical symptoms to challenges to social inclusion was almost entirely mediated (98\%) through mental health symptoms and impairments (Figure 2). Mental health appears to be a major predictor of social inclusion, even if adjusted for physical symptoms and difficulties carrying out day-to-day activities. Mental health (specifically cognition) can significantly impact social participation such as employment for adults with HIV [51, 52]. However, Rueda et al (2011) also suggested the reverse relationship whereby employment is associated with better mental and physical health-related quality of life [53]. Given the crosssectional nature of this study, the direction of causation is unknown, suggesting the dual importance of clinically addressing mental health challenges for people living with HIV as well as educating employers and policy makers to facilitate labor force participation and social inclusion for this population [53]. The impact of mental health on other components of social inclusion in our model, such as housing, is less clear [54]. Findings from a qualitative study suggested a relationship between housing and mental health; however the direction of this relationship is unknown [55]. Nevertheless, findings from this SEM analysis highlight the importance for health care providers to consider strategies that may prevent or mitigate physical symptoms and mental health symptoms experienced by adults living with HIV in order to enhance their ability to carry out daily activities, and participate in society, respectively.

Findings also suggest that physical symptoms experienced frequently by people living with HIV, such as pain and loss of energy, may not necessarily lead to challenges to social inclusion, such as problems with income, housing, or employment, without concurrent mental health problems such as depression and anxiety. This suggests that empirically supported mental health interventions for people living with HIV, such as cognitive behavioral therapies, may not only reduce psychological distress but also may be associated with reductions in social 
aspects of disability [56-58].

\section{Implications for Future Practice and Policy}

As individuals live longer and age with HIV, they may be living with multiple morbidities, adding further severity and complexity of disability experienced with HIV. Findings from this analysis highlight the importance for health providers to consider the spectrum of disability in their assessment and the potential for extrinsic and intrinsic contextual factors within the Episodic Disability Framework to serve as interventions that may mitigate or prevent disability among adults with HIV. Contextual factors including social support, stigma and living strategies may interact with and influence dimensions of disability, highlighting interventions that may help to address disability. Evidence supports the role of social support (emotional, practical informational) as a mechanism to reduce depression, enhance function and adherence to antiretroviral therapy $[59,60]$ whereas, HIV-related stigma is significantly associated with increased depression, decreased cognitive function, and decreased energy levels [61], Interventions aimed at enhancing social support and reducing stigma may help alleviate physical and mental health symptoms and impairments for people with HIV. Living strategies, an intrinsic contextual factor in the Framework that includes seeking social interaction with others, maintaining a sense of control, and adopting attitudes of hope and resiliency, also highlight strategies clinicians and people with HIV may use to manage the health challenges of HIV. Adopting lifestyle modifications to maximize health (getting adequate nutrition and sleep, reducing substance use, adhering to medications, exercising, avoiding external stressors and ensuring financial security); establishing a sense of purpose in life; creating a daily structure or routine, and prioritizing tasks and planning for and anticipating the future, offer possible interventions clinicians may consider with their patients [15]. Specifically, cognitive-behavioral 
and stress management interventions have been used to address anxiety and depression and enhance coping among people with HIV [56-58, 62-64]. Overall findings highlight the importance for health providers and policy makers to consider the role of extrinsic and intrinsic contextual factors (programs, services and interventions) in addressing disability experienced by people living with HIV.

Using SEM enabled us to simultaneously determine both direct and indirect effects among multiple latent variables representing disability however, our study possessed limitations. Results are limited to the characteristics of participants who were healthy enough to complete the 90-120 minute OCS questionnaire, the majority of who were men, in their 40s, taking antiretroviral therapy, and not currently working. Generalization to other individuals and settings remains to be determined. Second, we were unable to suggest causality between the dimensions of disability due to the cross-sectional nature of the analysis. Physical and mental health latent variables are often modeled as correlated with each other because of the longstanding uncertainty of their cause and effect $[22,65]$. We hypothesized a direct relationship from physical symptoms to mental health symptoms and impairments in our structural model to assess potential indirect effects between physical health and social inclusion, a hypothesis supported by literature that suggested physical health predicts mental health [66]. However alternative hypotheses could be that mental health symptoms directly predict physical health symptoms, or that the relationship between physical symptoms and mental health symptoms exists in a feedback loop, whereby physical symptoms directly predict mental health symptoms and vice versa. This bidirectional relationship, known as reciprocal causation, would result in a non-recursive model increasing the complexity of the analysis which commonly leads to problems with identification [35]. Hence, we assessed the relationships of disability using an advisable recursive (or 
unidirectional) model in our analyses [67]. Future longitudinal analyses may help determine whether one latent variable precedes the other.

\section{Implications Future Research}

This analysis lays a foundation for future research on disability in the context of HIV. While the focus of our analysis was on the first component of the Episodic Disability Framework (dimensions of disability), future modeling also may determine the influence of extrinsic and intrinsic contextual factors, such as stigma, social support, and living strategies, as well as triggers, on dimensions of disability in Episodic Disability Framework [15]. Findings will help empirically identify specific areas to target interventions to reduce disability experienced by adults living with HIV. Future research also may adjust for personal attributes such as age, gender, antiretroviral use, length of time since diagnosis or other health conditions, such as Hepatitis $\mathrm{C}$ co-infection, to determine if they have a moderating effect on disability. For instance, antiretroviral use is associated with lower physical function (independent of CD4 count and viral load) and enhanced mental health function [68-70]. However, this evidence is specific to quality of life; the influence of immunological and virological indices, and adherence to combination antiretroviral therapy on dimensions of disability is unclear. Finally, uncertainty, a dimension of disability in the Episodic Disability Framework, was not considered in our analysis as no measures in the OCS currently captured this dimension. Future research should assess the relationships between uncertainty and other disability dimensions in the Framework.

\section{CONCLUSIONS}

We empirically tested relationships between four dimensions of disability in the Episodic Disability Framework. Physical symptoms and impairments, mental health symptoms and 
impairments and difficulties with day-to-day activities directly or indirectly predict challenges to social inclusion. Challenges to social inclusion are directly predicted by mental health symptoms and indirectly by physical health symptoms mediated by difficulties carrying out day-to-day activities and mental health symptoms. These findings provide a basis for conceptualizing disability among people living with HIV and may help to indicate areas in which health care providers may target interventions to reduce dimensions of disability. 


\section{ACKNOWLEGEMENTS}

This work was supported by the Canadian Institutes of Health Research (CIHR) and McMaster University DeGroote Postdoctoral Fellowship. Kelly O’Brien was supported by a Fellowship from the CIHR, HIV/AIDS Research Initiative. Trevor Hart is supported by an OHTN Career Scientist Award. We thank Carolina BarnettTapia for translating the abstract into Spanish.

*The OHTN Cohort Study Team consists of Dr. Sean B. Rourke (Principal Investigator, University of Toronto and OHTN), Dr. Ann Burchell (Co-Principal Investigator, OHTN), Dr. Sandra Gardner (OHTN), Dr. Sergio Rueda (OHTN), Dr. Ahmed Bayoumi, St. Michael's Hospital; Dr. Jeffrey Cohen, Windsor Regional Hospital; Dr. Curtis Cooper, Ottawa General Hospital; Dr. Don Kilby, University of Ottawa Health Services; Dr. Mona Loutfy and Dr. Fred Crouzat, Maple Leaf Medical Clinic; Dr. Anita Rachlis and Dr. Nicole Mittmann, Sunnybrook Health Sciences Centre; Dr. Janet Raboud and Dr. Irving Salit, Toronto General Hospital; Dr. Edward Ralph, St. Joseph's Health Care; Dr. Roger Sandre, Sudbury Regional Hospital; Dr. Marek Smieja, Hamilton Health Sciences, McMaster University Medical Centre; and Dr. Wendy Wobeser, Hotel Dieu Hospital.

We gratefully acknowledge all of the people living with HIV who volunteered to participate in the OHTN Cohort Study and the work and support of the past and present members of the OCS Governance Committee: Dr. Evan Collins, Dr. Greg Robinson, Shari Margolese, Patrick Cupido, Tony Di Pede, Rick Kennedy, Michael J. Hamilton, Ken King, Brian Finch, Lori Stoltz, Dr. Ahmed Bayoumi, Dr. Clemon George, Dr. Curtis Cooper, Dr. Troy Grennan, Adrian Betts, Tracey Conway, and Colleen Price. We thank all the interviewers, data collectors, research associates and coordinators, nurses and physicians who provide support for data collection and extraction. The authors wish to thank the OHTN staff and their teams for data management and 
IT support (Mark Fisher, Director, IT), and OCS project coordination (Samantha Robinson, Project Coordinator). The OHTN Cohort Study is supported by the Ontario Ministry of Health and Long-Term Care. The opinions, results and conclusions are those of the authors and no endorsement by the Ontario HIV Treatment Network is intended or should be inferred. 


\section{REFERENCES}

1. Vance DE, Mugavero M, Willig J, Raper JL, Saag MS. Aging With HIV: A CrossSectional Study of Comorbidity Prevalence and Clinical Characteristics Across Decades of Life. J Assoc Nurses AIDS Care. 2011;22(1):17-25.

2. Balogun JA, Kaplan MT, Miller TM. The effect of professional education on the knowledge and attitudes of physical therapist and occupational therapist students about acquired immunodeficiency syndrome. Physical Therapy. 1998;78(10):1073-82.

3. Brown TT, Qaqish RB. Antiretroviral therapy and the prevalence of osteopenia and osteoporosis: a meta-analytic review. AIDS. 2006;20(17):2165-74. Epub 2006/11/07.

4. Heaton RK, Clifford DB, Franklin DR, Jr., et al. HIV-associated neurocognitive disorders persist in the era of potent antiretroviral therapy: CHARTER Study. Neurology. 2011;75(23):2087-96. Epub 2010/12/08.

5. Shiels MS, Cole SR, Kirk GD, Poole C. A meta-analysis of the incidence of non-AIDS cancers in HIV-infected individuals. J Acquir Immune Defic Syndr. 2009;52(5):611-22. Epub 2009/09/23.

6. Weiss JJ, Osorio G, Ryan E, Marcus SM, Fishbein DA. Prevalence and patient awareness of medical comorbidities in an urban AIDS clinic. AIDS Patient Care STDS. 2010;24(1):39-48. Epub 2010/01/26.

7. Willard S, Holzemer WL, Wantland DJ, et al. Does "asymptomatic" mean without symptoms for those living with HIV infection? AIDS Care. 2009;21(3):322-8. Epub 2009/03/13.

8. Gaidhane AM, Syed Zahiruddin Q, Waghmare L, Zodpey S, Goyal RC, Johrapurkar SR. Assessing self-care component of activities and participation domain of the international 
classification of functioning, disability and health (ICF) among people living with HIV/AIDS. AIDS Care. 2008:1-7. Epub 2008/07/09.

9. Hasse B, Ledergerber B, Furrer H, et al. Morbidity and aging in HIV-infected persons: the Swiss HIV cohort study. Clin Infect Dis. 2011;53(11):1130-9. Epub 2011/10/15.

10. Guaraldi G, Orlando G, Zona S, et al. Premature age-related comorbidities among HIVinfected persons compared with the general population. Clin Infect Dis. 2011;53(11):11206. Epub 2011/10/15.

11. Rusch M, Nixon S, Schilder A, Braitstein P, Chan K, Hogg RS. Impairments, activity limitations and participation restrictions: prevalence and associations among persons living with HIV/AIDS in British Columbia. Health Qual Life Outcomes. 2004;2:46.

12. Blanch J, Rousaud A, Martinez E, et al. Factors associated with severe impact of lipodystrophy on the quality of life of patients infected with HIV-1. Clin Infect Dis. 2004;38(10):1464-70.

13. Brooks RA, Martin DJ, Ortiz DJ, Veniegas RC. Perceived barriers to employment among persons living with HIV/AIDS. AIDS Care. 2004;16(6):756-66. Epub 2004/09/17.

14. O'Brien KK, Bayoumi AM, Strike C, Young NL, Davis AM. Exploring disability from the perspective of adults living with HIV/AIDS: development of a conceptual framework. Health Qual Life Outcomes. 2008;6:76. Epub 2008/10/07.

15. O'Brien KK, Davis AM, Strike C, Young NL, Bayoumi AM. Putting episodic disability into context: a qualitative study exploring factors that influence disability experienced by adults living with HIV/AIDS. J Int AIDS Soc. 2009;12(1):5. Epub 2009/11/11. 
16. Nagi S. Some conceptual issues in disability and rehabilitation. In: Sussman M, editor. Sociology and Rehabilitation. Washington, DC: American Sociological Association; 1965. p. $100-13$.

17. Nagi S. Disability concepts revisited: implications for prevention. In: Pope A, Tarlov A, editors. Disability in America: Toward a National Agenda for Prevention. Washington, DC: National Academy Press; 1991. p. 309-27.

18. World Health Organization. International classification of impairments, disabilities and handicaps (ICIDH). Geneva: The World Health Organization; 1980.

19. Verbrugge LM, Jette AM. The disablement process. Soc Sci Med. 1994;38(1):1-14.

20. Fougeyrollas P, St-Michel G, Bergeron N, Cloutier R. The handicap creation process: analysis of the consultation. ICIDH International Network. 1991;4:8-37.

21. World Health Organization. International classification of functioning, disability and health (ICF). Geneva.: The World Health Organization; 2001.

22. Wilson IB, Cleary PD. Linking clinical variables with health-related quality of life. A conceptual model of patient outcomes. Jama. 1995;273(1):59-65.

23. Jette AM, Badley E. Chapter 2: Conceptual Issues in the Measurement of Disability Survey Measurement of Work Disability: Summary of a Workshop: National Academies Press, National Research Council; 2000.

24. Vidrine DJ, Amick BC, 3rd, Gritz ER, Arduino RC. Assessing a conceptual framework of health-related quality of life in a HIV/AIDS population. Qual Life Res. 2005;14(4):923-33. Epub 2005/07/27. 
25. Sousa KH, Kwok OM. Putting Wilson and Cleary to the test: analysis of a HRQOL conceptual model using structural equation modeling. Qual Life Res. 2006;15(4):725-37. Epub 2006/05/12.

26. Ryu E, West SG, Sousa KH. Mediation and moderation: Testing relationships between symptom status, functional health, and quality of life in HIV patients. Multivariate Behav Res. 2009;44(2):213-32. Epub 2009/03/01.

27. Rourke SB, Gardner S, Burchell AN, et al. Cohort Profile: The Ontario HIV Treatment Network Cohort Study (OCS). International journal of epidemiology. 2012. Epub $2012 / 02 / 22$.

28. Justice AC, Holmes W, Gifford AL, et al. Development and validation of a self-completed HIV symptom index. J Clin Epidemiol. 2001;54 Suppl 1:S77-90.

29. Ware JE, Jr. SF-36 health survey update. Spine (Phila Pa 1976). 2000;25(24):3130-9. Epub $2000 / 12 / 22$.

30. Ware JE, Jr., Gandek B. Overview of the SF-36 Health Survey and the International Quality of Life Assessment (IQOLA) Project. J Clin Epidemiol. 1998;51(11):903-12. Epub 1998/11/17.

31. Brooks R, Rabin R, Charro F. The measurement and valuation of health status using EQ5D: A European perspective. Dordrecht, The Netherlands: Kluwer Academic Publishers; 2003.

32. Wu AW, Revicki DA, Jacobson D, Malitz FE. Evidence for reliability, validity and usefulness of the Medical Outcomes Study HIV Health Survey (MOS-HIV). Qual Life Res. 1997;6(6):481-93. 
33. Radloff LS. The CES-D scale: A self-report depression scale for research in the general population. Applied Psychological Measurement. 1977;1(3):385-401.

34. Statistics Canada. National population health survey household component documentation for the derived variables and the constant longitudinal variables (specifications): Cycles 1 to 7 (1994/1995 to 2006/2007). Ottawa: Statistics Canada, 2008.

35. Kline RB. Principles and practice of structural equation modeling. New York, NY: The Guilford Press; 2005.

36. O'Brien K, Hanna S, Bayoumi AM, et al. Exploring relationships between dimensions of disability: A revised measurement model. Can J Infect Dis Med Microbiology. 2010;21(Suppl B):71B.

37. O'Brien KK, Bayoumi AM, Strike C, Young NL, King K, Davis AM. How do existing HIV-specific instruments measure up? Evaluating the ability of instruments to describe disability experienced by adults living with HIV. Health Qual Life Outcomes. 2010;8:88. Epub 2010/08/21.

38. Carter SL, Rourke SB, Murji S, Shore D, Rourke BP. Cognitive complaints, depression, medical symptoms, and their association with neuropsychological functioning in HIV infection: a structural equation model analysis. Neuropsychology. 2003;17(3):410-9. Epub 2003/09/10.

39. Muthen LK, Muthen BO. Mplus Version 6.0. Los Angeles, CA2010.

40. Muthen LK, Muthen BO. Mplus User's Guide 6th Edition. Los Angeles, CA1998-2010.

41. Hu LT, Bentler PM. Cutoff criteria for fit indexes in covariance structure analysis: conventional criteria versus new alternatives. Structural Equation Modeling. 1999;6(1-55). 
42. Rigdon EE. CFI versus RMSEA: A comparison of two fit indexes for structural equation modeling. Structural Equation Modeling. 1996;3(4):369-79.

43. Brown TA. Confirmatory factor analysis for applied research. New York, NY: The Guilford Press; 2006.

44. Crystal S, Fleishman JA, Hays RD, Shapiro MF, Bozzette SA. Physical and role functioning among persons with HIV: results from a nationally representative survey. Medical Care. 2000;38(12):1210-23.

45. Hudson AL, Lee KA, Portillo CJ. Symptom experience and functional status among HIVinfected women. AIDS Care. 2003;15(4):483-92. Epub 2003/09/27.

46. Burgoyne RW, Rourke SB, Behrens DM, Salit IE. Long-term quality-of-life outcomes among adults living with HIV in the HAART era: the interplay of changes in clinical factors and symptom profile. AIDS Behav. 2004;8(2):151-63. Epub 2004/06/10.

47. Wachtel T, Piette J, Mor V, Stein M, Fleishman J, Carpenter C. Quality of life in persons with human immunodeficiency virus infection: measurement by the Medical Outcomes Study instrument. Ann Intern Med. 1992;116(2):129-37.

48. Cleary PD, Fowler FJ, Jr., Weissman J, et al. Health-related quality of life in persons with acquired immune deficiency syndrome. Medical Care. 1993;31(7):569-80.

49. Sousa KH, Tann SS, Kwok OM. Reconsidering the assessment of symptom status in HIV/AIDS care. J Assoc Nurses AIDS Care. 2006;17(2):36-46. Epub 2006/06/28.

50. Sousa KH, Holzemer WL, Henry SB, Slaughter R. Dimensions of health-related quality of life in persons living with HIV disease. J Adv Nurs. 1999;29(1):178-87. Epub 1999/03/04. 
51. Albert SM, Marder K, Dooneief G, et al. Neuropsychologic impairment in early HIV infection. A risk factor for work disability. Archives of neurology. 1995;52(5):525-30. Epub 1995/05/01.

52. Heaton RK, Velin RA, McCutchan JA, et al. Neuropsychological impairment in human immunodeficiency virus-infection: implications for employment. HNRC Group. HIV Neurobehavioral Research Center. Psychosom Med. 1994;56(1):8-17. Epub 1994/01/01.

53. Rueda S, Raboud J, Mustard C, Bayoumi AM, Lavis JN, Rourke SB. Employment status is associated with both physical and mental health quality of life in people living with HIV. AIDS Care. 2011;23(4):435-43. Epub 2011/01/29.

54. Leaver CA, Bargh G, Dunn JR, Hwang SW. The effects of housing status on health-related outcomes in people living with HIV: a systematic review of the literature. AIDS Behav. 2007;11(6 Suppl):85-100. Epub 2007/08/09.

55. Greene S, Tucker R, Rourke SB, et al. Housing Instability and People Living with HIV/AIDS in Ontario: the impact of housing instability on mental health. Can J Infect Dis Med Microbiology. 2009;20(Suppl B):106B.

56. Safren SA, O'Cleirigh C, Tan JY, et al. A randomized controlled trial of cognitive behavioral therapy for adherence and depression (CBT-AD) in HIV-infected individuals. Health Psychol. 2009;28(1):1-10. Epub 2009/02/13.

57. Himelhoch S, Mohr D, Maxfield J, et al. Feasibility of telephone-based cognitive behavioral therapy targeting major depression among urban dwelling African-American people with co-occurring HIV. Psychology, health \& medicine. 2011;16(2):156-65. Epub 2011/02/18. 
58. Antoni MH, Cruess DG, Cruess S, et al. Cognitive-behavioral stress management intervention effects on anxiety, 24-hr urinary norepinephrine output, and Tcytotoxic/suppressor cells over time among symptomatic HIV-infected gay men. Journal of consulting and clinical psychology. 2000;68(1):31-45. Epub 2000/03/11.

59. Luszczynska A, Sarkar Y, Knoll N. Received social support, self-efficacy, and finding benefits in disease as predictors of physical functioning and adherence to antiretroviral therapy. Patient Educ Couns. 2007;66(1):37-42. Epub 2006/11/14.

60. Hays RB, Turner H, Coates TJ. Social support, AIDS-related symptoms, and depression among gay men. Journal of consulting and clinical psychology. 1992;60(3):463-9. Epub 1992/06/01.

61. Grov C, Golub SA, Parsons JT, Brennan M, Karpiak SE. Loneliness and HIV-related stigma explain depression among older HIV-positive adults. AIDS Care. 2010;22(5):630-9. Epub 2010/04/20.

62. Harding R, Liu L, Catalan J, Sherr L. What is the evidence for effectiveness of interventions to enhance coping among people living with HIV disease? A systematic review. Psychology, health \& medicine. 2011;16(5):564-87. Epub 2011/08/27.

63. Sherr L, Clucas C, Harding R, Sibley E, Catalan J. HIV and depression--a systematic review of interventions. Psychology, health \& medicine. 2011;16(5):493-527. Epub $2011 / 08 / 04$

64. Clucas C, Sibley E, Harding R, Liu L, Catalan J, Sherr L. A systematic review of interventions for anxiety in people with HIV. Psychology, health \& medicine. 2011;16(5):528-47. Epub 2011/07/23. 
65. Hays RD, Marshall GN, Wang EY, Sherbourne CD. Four-year cross-lagged associations between physical and mental health in the Medical Outcomes Study. Journal of consulting and clinical psychology. 1994;62(3):441-9. Epub 1994/06/01.

66. Cho J, Martin P, Margrett J, Macdonald M, Poon LW. The Relationship between Physical Health and Psychological Well-Being among Oldest-Old Adults. Journal of aging research. 2011;2011:605041. Epub 2011/07/13.

67. Bryan A, Schmiege SJ, Broaddus MR. Mediational analysis in HIV/AIDS research: estimating multivariate path analytic models in a structural equation modeling framework. AIDS Behav. 2007;11(3):365-83. Epub 2006/08/19.

68. Gill CJ, Griffith JL, Jacobson D, Skinner S, Gorbach SL, Wilson IB. Relationship of HIV viral loads, CD4 counts, and HAART use to health-related quality of life. J Acquir Immune Defic Syndr. 2002;30(5):485-92. Epub 2002/08/03.

69. Weinfurt KP, Willke RJ, Glick HA, Freimuth WW, Schulman KA. Relationship between CD4 count, viral burden, and quality of life over time in HIV-1-infected patients. Med Care. 2000;38(4):404-10. Epub 2001/02/07.

70. Liu C, Ostrow D, Detels R, et al. Impacts of HIV infection and HAART use on quality of life. Qual Life Res. 2006;15(6):941-9. Epub 2006/08/11. 
Fig. 1: Hypothesized Structural Model of Relationships between Dimensions of Disability

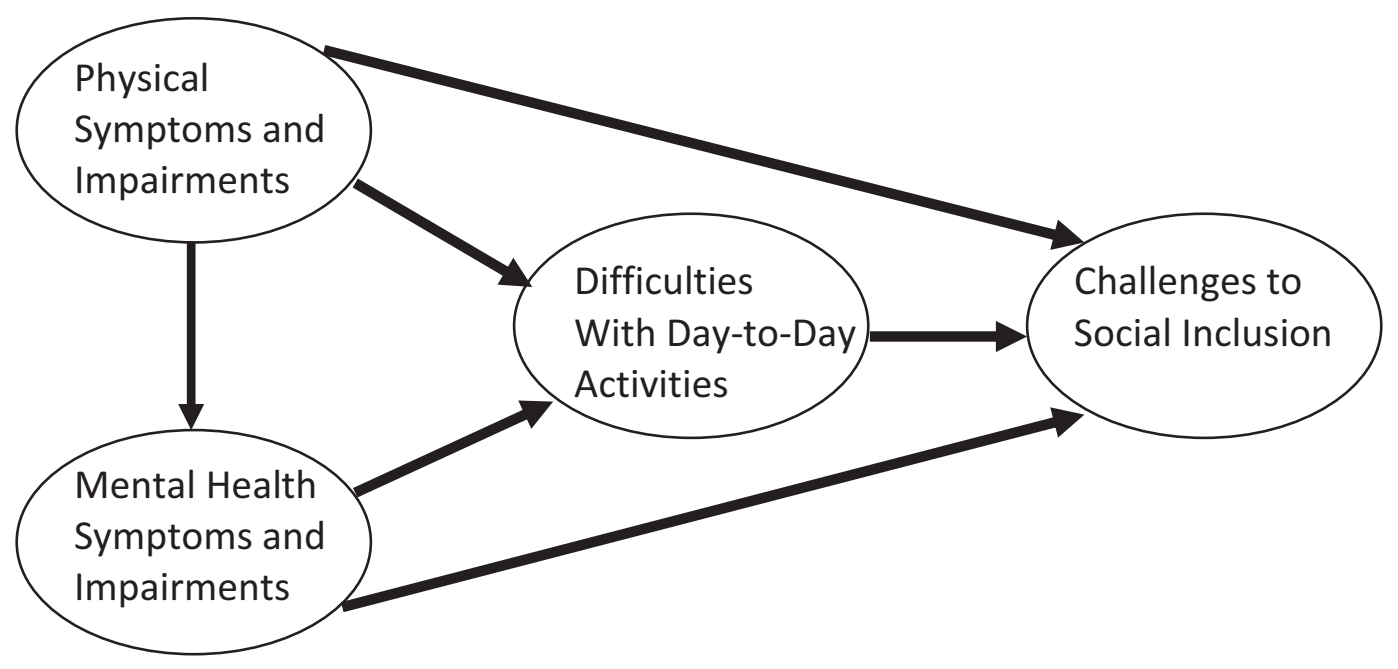


Fig. 2: Final Structural Model of Relationships between Dimensions of Disability ( $n=913$ participants)

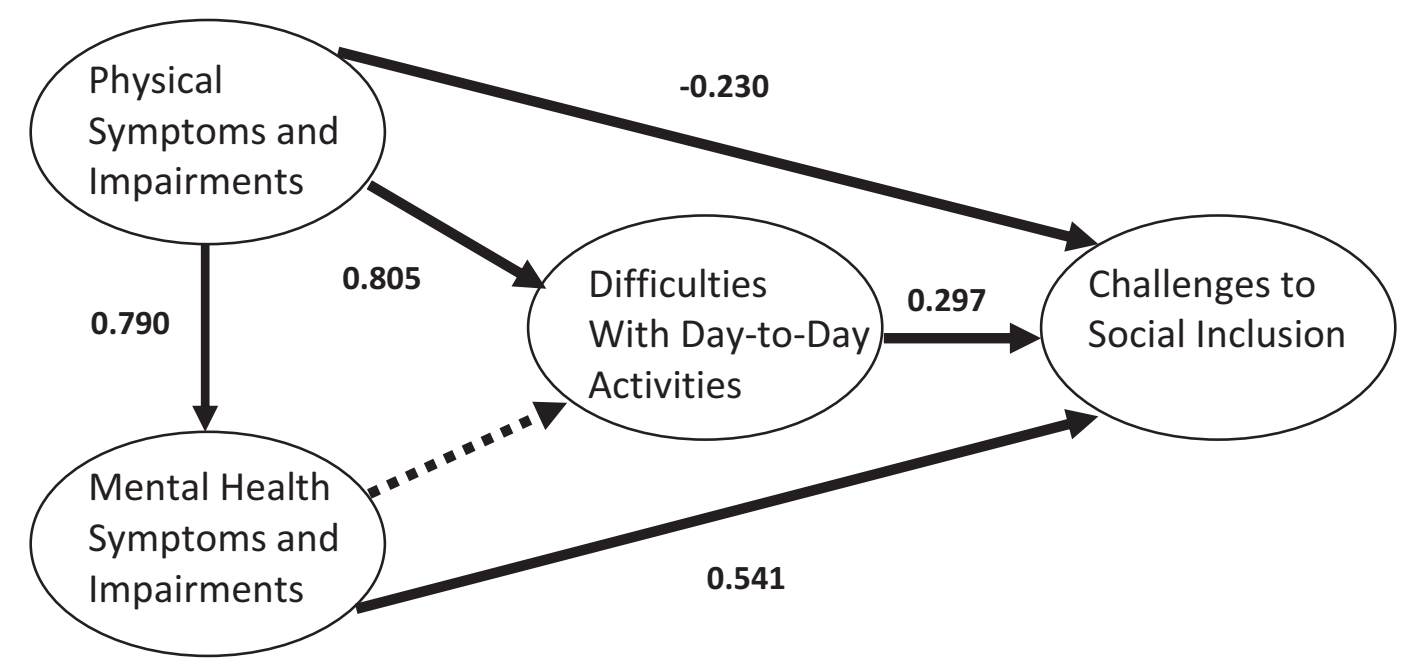

\section{Fig. 2 Legend}

Relationships between dimensions of disability represented by standardized parameter estimates. Solid lines represent significant relationships between dimensions of disability $(p<0.05)$. Dotted lines represent non-significant relationships between dimensions of disability. Indirect Effects: The relationship between physical symptoms and impairments to challenges to social inclusion is mediated by difficulties with day-to-day activities $(0.805 \times 0.297=0.239)$ and mental health symptoms and impairments $(0.790 \times 0.541=0.427)$ 
Table 1: Characteristics of Participants ( $n=913)$

\begin{tabular}{|c|c|}
\hline Characteristic & Number (\%) \\
\hline \multicolumn{2}{|l|}{ Gender } \\
\hline Male & $757(83 \%)$ \\
\hline Female & $153(17 \%)$ \\
\hline Other* & $3(<1 \%)$ \\
\hline Age (median; IQR) & 47 years ( $41-53$ years) \\
\hline Length of Time Since Diagnosis (median; IQR) & 11 years (6-17 years) \\
\hline Taking Antiretrovirals & $783(86 \%)$ \\
\hline \multicolumn{2}{|l|}{ Race } \\
\hline White & $588(64 \%)$ \\
\hline Black / African & $158(17 \%)$ \\
\hline Asian / Latin American / Arab & $101(11 \%)$ \\
\hline Aboriginal & $22(2 \%)$ \\
\hline \multicolumn{2}{|l|}{ Employment Status } \\
\hline Employed (full time or part time) & $412(45 \%)$ \\
\hline On disability leave from work & $289(32 \%)$ \\
\hline Student or retired & $106(12 \%)$ \\
\hline Unemployed & 79 (9\%) \\
\hline Volunteering & $25(3 \%)$ \\
\hline \multicolumn{2}{|l|}{ Educational Level } \\
\hline No formal education or less than grade 9 & $32(3 \%)$ \\
\hline Partially or fully completed high school education & $268(29 \%)$ \\
\hline Partially or fully completed trade or technical training & $31(3 \%)$ \\
\hline Partially or fully completed college & $234(26 \%)$ \\
\hline Partial or fully completed university & $279(31 \%)$ \\
\hline Post-graduate education & $69 \quad(8 \%)$ \\
\hline \multicolumn{2}{|l|}{ Gross Personal Income (Canadian dollars) } \\
\hline Less than $\$ 20,000$ per year & $386(43 \%)$ \\
\hline$\$ 20,000$ to less than $\$ 40,000$ per year & $214(24 \%)$ \\
\hline$\$ 40,000$ to less than $\$ 60,000$ per year & $140(16 \%)$ \\
\hline
\end{tabular}




$\begin{array}{lll}\$ 60,000 \text { to less than } \$ 80,000 \text { per year } & 70 & (8 \%) \\ \$ 80,000 \text { or more per year } & 85 & (9 \%)\end{array}$

IQR=interquartile range. Not all characteristics add to the total $\mathrm{n}$ due to missing responses.

*Other=trans, inter-sexed or other. 
Table 2 -Measurement Model of Dimensions of Disability

\begin{tabular}{|c|c|c|c|c|}
\hline $\begin{array}{l}\text { Dimension of } \\
\text { Disability }\end{array}$ & Variables in OCS Questionnaire & $\begin{array}{l}\text { Cronbach's } \\
\text { Alpha^ }^{-1}\end{array}$ & $\begin{array}{l}\text { Standardized } \\
\text { Factor } \\
\text { Loadings\# }\end{array}$ & $\begin{array}{l}95 \% \\
\text { Confidence } \\
\text { Interval } \\
\end{array}$ \\
\hline \multirow{21}{*}{$\begin{array}{l}\text { Physical } \\
\text { Symptoms and } \\
\text { Impairments } \\
\text { ( } \mathrm{n}=21 \\
\text { variables) }\end{array}$} & HIV Symptom Index - Loss of Energy & -- & 0.78 & $0.74-0.81$ \\
\hline & HIV Symptom Index - Chills or Sweats & -- & 0.64 & $0.58-0.69$ \\
\hline & HIV Symptom Index - Feeling Dizzy & -- & 0.68 & $0.63-0.73$ \\
\hline & HIV Symptom Index - Pain & -- & 0.69 & $0.64-0.73$ \\
\hline & HIV Symptom Index - Nausea & -- & 0.63 & $0.57-0.69$ \\
\hline & HIV Symptom Index - Diarrhea & -- & 0.50 & $0.44-0.56$ \\
\hline & $\begin{array}{l}\text { HIV Symptom Index - Difficulty } \\
\text { Sleeping }\end{array}$ & -- & 0.65 & $0.60-0.70$ \\
\hline & HIV Symptom Index - Skin Problems & -- & 0.51 & $0.44-0.57$ \\
\hline & HIV Symptom Index - Cough & -- & 0.58 & $0.52-0.64$ \\
\hline & HIV Symptom Index - Headache & -- & 0.59 & $0.53-0.65$ \\
\hline & HIV Symptom Index - Loss of Appetite & -- & 0.64 & $0.58-0.69$ \\
\hline & HIV Symptom Index - Bloating & -- & 0.59 & $0.54-0.65$ \\
\hline & HIV Symptom Index - Muscle Aches & -- & 0.75 & $0.71-0.79$ \\
\hline & HIV Symptom Index - Problems Sex & -- & 0.50 & $0.43-0.56$ \\
\hline & HIV Symptom Index - Body & -- & 0.35 & $0.28-0.43$ \\
\hline & HIV Symptom Index - Weight & -- & 0.41 & $0.33-0.48$ \\
\hline & HIV Symptom Index - Hair Loss & -- & 0.47 & $0.39-0.55$ \\
\hline & SF-36 Bodily Pain Subscale Score & 0.79 & 0.74 & $0.70-0.78$ \\
\hline & SF-36 Vitality Subscale Score & 0.86 & 0.82 & $0.79-0.85$ \\
\hline & SF-36 Social Function Subscale Score* & 0.85 & 0.21 & $0.13-0.28$ \\
\hline & EQ-5D Pain & -- & 0.77 & $0.73-0.81$ \\
\hline \multirow{10}{*}{$\begin{array}{l}\text { Mental Health } \\
\text { Symptoms and } \\
\text { Impairments } \\
\text { ( } \mathrm{n}=10 \\
\text { variables) }\end{array}$} & $\begin{array}{l}\text { HIV Symptom Index - Trouble } \\
\text { Remembering }\end{array}$ & -- & 0.67 & $0.61-0.72$ \\
\hline & HIV Symptom Index - Felt Sad & -- & 0.80 & $0.76-0.83$ \\
\hline & HIV Symptom Index - Felt Nervous & -- & 0.75 & $0.71-0.79$ \\
\hline & SF-36 Role Emotional Subscale Score & 0.90 & 0.78 & $0.74-0.81$ \\
\hline & SF-36 Mental Health Subscale Score & 0.86 & 0.82 & $0.79-0.84$ \\
\hline & SF-36 Social Function Subscale Score* & 0.85 & 0.61 & $0.54-0.68$ \\
\hline & $\begin{array}{l}\text { MOS Cognitive Function Summary } \\
\text { Score }\end{array}$ & 0.88 & 0.74 & $0.71-0.78$ \\
\hline & EQ-5D Anxiety and Depression Score & -- & 0.79 & $0.76-0.83$ \\
\hline & CES-D Total Summary Score & 0.73 & 0.86 & 0.84-0.89 \\
\hline & $\begin{array}{l}\text { Ongoing Problems Stress Index } \\
\text { Summary Score }\end{array}$ & 0.69 & 0.54 & $0.49-0.60$ \\
\hline
\end{tabular}




\begin{tabular}{|lllll|}
\hline Difficulties & SF-36 Physical Function Subscale Score & 0.91 & 0.73 & $0.69-0.76$ \\
\cline { 2 - 5 } $\begin{array}{l}\text { with Day-to- } \\
\text { Day Activities } \\
\text { (n=5 variables) }\end{array}$ & SF-36 Role Physical Function Subscale & 0.93 & 0.86 & $0.81-0.90$ \\
& Score & & & \\
\cline { 2 - 5 } & EQ-5D Mobility & -- & 0.76 & $0.71-0.82$ \\
\cline { 2 - 5 } & EQ-5D Self Care & -- & 0.61 & $0.50-0.72$ \\
\cline { 2 - 5 } & EQ-5D Usual Activities & -- & 0.89 & $0.85-0.94$ \\
\hline Challenges to & Dwelling & -- & 0.41 & $0.21-0.61$ \\
\cline { 2 - 5 } $\begin{array}{l}\text { Social } \\
\text { Inclusion } \\
\text { (n=8 variables) }\end{array}$ & Belonging in Neighborhood & -- & 0.48 & $0.40-0.55$ \\
\cline { 2 - 5 } & Home Good Location to Live & -- & 0.50 & $0.43-0.57$ \\
\cline { 2 - 5 } & Control at Home & -- & 0.57 & $0.50-0.64$ \\
\cline { 2 - 5 } & Employment Status & -- & 0.62 & $0.54-0.70$ \\
\cline { 2 - 5 } & Difficulty with Housing Costs & -- & 0.65 & $0.57-0.73$ \\
\cline { 2 - 5 } & Worry about Moving out of Home & - & 0.59 & $0.52-0.61$ \\
\cline { 2 - 5 } & Gross Personal Income & &
\end{tabular}

Measurement Model Results

$\chi^{2}=$ Chi-square $\left(\chi^{2}\right)=2621.50$ ( $p$ value $\left.<0.0001\right)$

Degrees of freedom $(\mathrm{df})=853$;

Comparative Fit Index (CFI) $=0.912$ (ideal is $\geq 0.95$ )

Tucker-Lewis Index (TLI) $=0.907$ (ideal is $\geq 0.95$ )

Root Mean Square Error of Approximation (RMSEA) $=0.048$ (good fit indicated by $<0.05$ )

Legend

HIV SI=HIV Symptom Index [28]; MOS=Medical Outcomes Study [32]; CES-D=Center for Epidemiologic Studies Depression Scale [33]; EQ-5D=EuroQOL questionnaire [31];

\# All standardized factor loadings were statistically significant $(p<0.0001)$;

*Indicates cross loading of SF-36 social function subscale score on two latent variables;

Factor loadings $\geq 0.30$ indicate the variable 'loads' on a given dimension of disability.

Any variables not identified as subscale or summary scores were individual item scores used in the analysis $(n=33)$.

${ }^{\wedge}$ Cronbach alphas are indicated for subscale and summary scores. 